\title{
FRAY PEDRO DE TAPIA, MENTOR DEL CONVENTO DE SAN ESTEBAN DE SALAMANCA
}

El convento dominico de San Esteban tuvo la fortuna de contar a lo largo de su historia con importantes patronos, que hicieron posible el espléndido conjunto arquitectónico que hoy contemplamos. Disfrutó también de aportaciones menores de muchos religiosos y hubo de empeñar no pocas veces sus propios bienes para poder culminar las obras emprendidas por aquéllos ${ }^{1}$. Me propongo destacar en este artículo una iniciativa de fray Pedro de Tapia prácticamente olvidada. Su interés radica en que, además de permitirnos precisar la fecha y artífices de la puerta del Claustro de los Reyes que marcó el modelo a seguir en otras tres, nos muestra al futuro prelado como un auténtico mentor, a pesar de la escasa cuantía de su desembolso si la comparamos con la de otros insignes dominicos de este mismo convento. Constituye además la primera obra artística que promueve este religioso, con la particularidad de que lo hace cuando todavía no gozaba de cargos ni de ninguna de las rentas episcopales que posteriormente le permitieron ofrecer magnánimos donativos ${ }^{2}$.

Fray Pedro de Tapia nació en Villoria (Salamanca) en marzo de 1582. Sus padres, el licenciado Diego Altanero y doña Isabel de Tapia, le llevaron muy joven a Salamanca para que comenzase el estudio de Artes en la Universidad, pero, a fines de siglo, siendo ya graduado en derecho civil y canónico, cambió su carrera de jurista por la de novicio dominico. El 28 de febrero de 1601, con 19 años, profesó en el convento de San Esteban, y su hermano Diego siguió su ejemplo. Relatan sus biógrafos las grandes contradicciones que sufrió en esta casa a causa de intervenciones diabólicas, que intentaban destruir el enorme prestigio que sus virtudes y su singular prudencia le habían granjeado ${ }^{3}$. Permaneció en el gran centro intelectual que entonces era San Esteban hasta 1618, ejerciendo desde 1607 su magisterio como profesor de filosofía. Pasó después a enseñar teología en los conventos de Plasencia, Segovia y Toledo, doctorándose en esta última ciudad. Desde abril de 1623 regentó en la Universidad de Alcalá la cátedra de Vísperas y, a partir del 27 de julio de 1630, la de Prima de Teología, fundadas por el duque de Lerma para la enseñanza de Santo Tomás ${ }^{4}$,

${ }^{1}$ Sobre la historia constructiva y artística de este convento y sus patronos, remitimos al excelente estudio de RoDRíguez G. DE Ceballos, A., La iglesia y el convento de San Esteban de Salamanca. Salamanca, Centro de Estudios Salmantinos, 1987; del mismo autor, "Patronos y mentores del Convento de San Esteban de Salamanca", en Lecturas de Historia del Arte, III, 1992, pp. 173-186.

${ }^{2}$ En 1638 encargó una escultura de la Virgen del Rosario a Manuel Pereira para el Colegio de Santo Tomás de Alcalá de Henares. En la catedral de Sigüenza costeó la reja del coro con las imágenes de la Virgen del Rosario, Santo Domingo de Guzmán y Santo Tomás de Aquino en la parte superior. Siendo obispo de Córdoba y electo de Sevilla, envió un donativo de 28.121 reales al convento de San Esteban para la construcción de la sillería del coro. En Sevilla, dio 20.000 ducados para que se concluyese el Sagrario con la condición expresa de que se le reservase la capilla mayor para su enterramiento. Todavía en vida, donó a esta iglesia una imagen de la Virgen del Rosario, de la órbita del escultor portugués Manuel Pereira, y regaló al cabildo el resto de las reliquias y esculturas de su oratorio. Agulló y CoBo, M., "Manuel Pereira: aportación documental", en B.S.A.A., 1978, p. 269. Federico, A. de, La Catedral de Sigüenza. Madrid, Plus Ultra, 1954, pp. 113-114. Rodríguez G. DE Ceballos, ob. cit., p. 67. Ros, C., Los arzobispos de Sevilla. Luces y sombras en la sede hispalense, Sevilla, 1986, pp. 186-190. Sobre su sepulcro y testamento, PALOMERo PÁramo, J. M., "El sepulcro del arzobispo dominico fray Pedro de Tapia", en Communio, vol. XXI (1988), pp. 209-224.

3 Sobre fray Pedro de Tapia, cf. Lorea, Fray Antonio de, El Siervo de Dios... don fr. Pedro de Tapia de la Orden de Predicadores, obispo de Segovia, Sigüenza, Córdova y arzobispo de Sevilla, Madrid, Imprenta Real, 1676. CuERvo, J., Historiadores del Convento de San Esteban. Salamanca, 1914, vol. I, pp. 720-742; vol. II, pp. 771-775; vol. III, pp. 609-610; Trapiello, F., "Fray Pedro de Tapia y su tiempo (1582-1657)", en Ciencia Tomista, tomo VI, 1913, pp. 396408, y Ciencia Tomista, tomo VII, 1913, pp. 228-252.

${ }_{4}$ Mora, Esteban O.P., Continuación de la Historia Annalística del Convento de San Esteban, orden de Predicadores de la ciudad de Salamanca. Tomo V, 1601-1630, ff. 463-464 y 970 (ms. Archivo del Convento de San Esteban). Beltrán de Heredia, P., "La enseñanza de Santo Tomás en la Universidad de Alcalá", en Ciencia Tomista, tomo XIV, 1916, pp. 267-297. 
hasta que fue promovido al obispado de Segovia en 1640. Posteriormente ocupó las mitras de Sigüenza (1645-1649) y Córdoba (1649-1652) y, tras haber declinado los arzobispados de Valencia y Santiago, fue obligado a aceptar el de Sevilla. Murió en esta ciudad en olor de santidad en 1657, iniciándose pocos años después su proceso de beatificación.

Antes de abandonar el convento de San Esteban, para dejar alguna memoria del afecto que sentía por esta casa, fray Pedro decidió costear la fábrica de la puerta de comunicación entre la portería y el Claustro de los Reyes. Dado que sus bienes eran muy limitados, para poder hacer frente a este gasto, tanto él como su hermano optaron por vender y traspasar a otro religioso del convento, fray Antonio Vázquez de Santo Domingo, diversos censos que gozaban contra varios vecinos de Villoria, cuyo valor ascendía a un total de 133.000 maravedís (poco más de 3.900 reales). En la escritura de venta fray Pedro Tapia alude expresamente al destino que dio a este dinero: "con los cuales hice hacer la portada y puertas del claustro del convento de San Esteban que se hizo a mi costa".

La construcción de esta portada se contrató el 28 de febrero de 1614 con Miguel de Ontiveros y su hijo Jerónimo, actuando como fiador el carpintero de la Universidad Cristóbal de Tolosa, suegro de este último ${ }^{6}$. Sorprende que habiendo trabajado en el convento, y concretamente en la portería, Pedro Gutiérrez no fuese el maestro elegido para su construcción. Lo más probable es que se pidieran diversas trazas y fray Pedro de Tapia eligió la que le pareció más conveniente. Por otra parte, muerto Ribero Rada, no debía existir profesionalmente mucha diferencia entre Pedro Gutiérrez, Juan de Nates, Miguel y Jerónimo de Ontiveros o Alonso Rodríguez, que son los canteros que ejecutan las principales obras salmantinas en la primera década del siglo XVII: en el convento benedictino de San Vicente, en el cisterciense de Nuestra Señora de Loreto, en el de mercedarios descalzos, etc. Los encontramos en algunos casos formando asociación, en otros pujando entre ellos o bien dando informes técnicos sobre trazas de unos y otros ${ }^{7}$. La mayoría habían recibido la influencia clasicista de Rada como ejecutores o continuadores que fueron de sus proyectos ${ }^{8}$, pero estaban lejos de haberla asimilado, como se puede ver en el ejemplo que nos ocupa. Pronto serán desplazados por Juan Moreno, Francisco de la Hoya o Alonso Sardiña.

\footnotetext{
5 Archivo Histórico Provincial de Salamanca (en adelante A.H.P.S.), Prot. 3758, Escritura a favor de fray Antonio Vázquez de Santo Domingo. 13 agosto de 1616, ff. 123-126.

${ }^{6}$ A.H.P.S., Prot. 3753, "Escritura entre el convento de san Estevan y Miguel de Ontiberos y su ijo". 28 de febrero de 1614 , ff. $266-269 v$.

${ }^{7}$ De hecho en 1603, Alonso Rodríguez y Miguel de Ontiveros fueron dos de los fiadores de Pedro Gutiérrez en la escritura de obligación suscrita con el convento de San Esteban para concluir el cimborrio. Todos ellos estuvieron asimismo implicados de alguna manera en la construcción del Patio de Escuelas, proyectado por la Universidad en 1609. Alonso Rodríguez, y después Pedro Gutiérrez, hicieron el proyecto, y para su ejecución además de éste pujaron Juan de Nates y Miguel de Ontiveros. Juan de Nates Naveda trabajó en el convento de la Madre de Dios, en el monasterio de Jesús, en el antiguo colegio de la Compañía y en el monasterio de la Vega. Miguel de Ontiveros y su hijo Jerónimo compitieron con él, con Alonso Rodríguez, Juan Moreno o el propio Pedro Gutiérrez en algunas de las obras, encargándose de terminar el claustro de San Bernardo y de distintos trabajos en los conventos de San Vicente, la Merced Descalza o San Leonardo de Alba, entre otros. Hernández, B., "Fase final de las obras en la iglesia de San Esteban", en Archivo Dominicano, 1982, pp. 276-277. Rupérez Almajano, M. a N., "La Universidad de Salamanca en la ciudad: aspectos urbanísticos (siglos XV-XVIII)", en Miscelánea Alfonso IX, 2002, pp. 127-134. RodríGUEZ G. de Ceballos, A. y Casaseca, A., "Juan del Ribero Rada y la introducción del clasicismo en Salamanca y Zamora", en Herrera y el Clasicismo, Valladolid, 1986, pp. 104-107. García Aguado, P., Documentos para la historia del arte en la provincia de Salamanca. Salamanca, Diputación, 1988, pp. 53-57. Redondo CANTERA, M. ${ }^{a}$ J.: "Apuntes para la historia del desaparecido convento de San Bernardo en Salamanca: su edificio", en B.S.A.A., tomo LVI (1991), pp. 444 y ss. Rodríguez G. DE Ceballos, A. "El primitivo colegio de la Compañía de Jesús en Salamanca (1545-1665)", en Miscelánea Comillas, 46 (1966), pp. 117-122. Barbero, A. y Miguel, T., Documentos para la historia del arte en la provincia de Salamanca. Salamanca, Diputación, 1987, pp. 202-205. García Catalán, E., El monasterio de San Vicente de Salamanca. Salamanca, Centro de Estudios Salmantinos, 2005, pp. 99-101.

${ }^{8}$ Esta relación la han resaltado, entre otros, Rodríguez G. De Ceballos, A. y Casaseca, A., art. cit., p. 107, y Campos SÁnchez-Bordona, M. a D., "Juan del Ribero Rada. Arquitecto clasicista”, en Altamira, LII (1997), pp. 83-101.
}

AEA, LXXXI, 321, ENERO-MARZO 2008, 67-76, ISSN: 0004-0428 


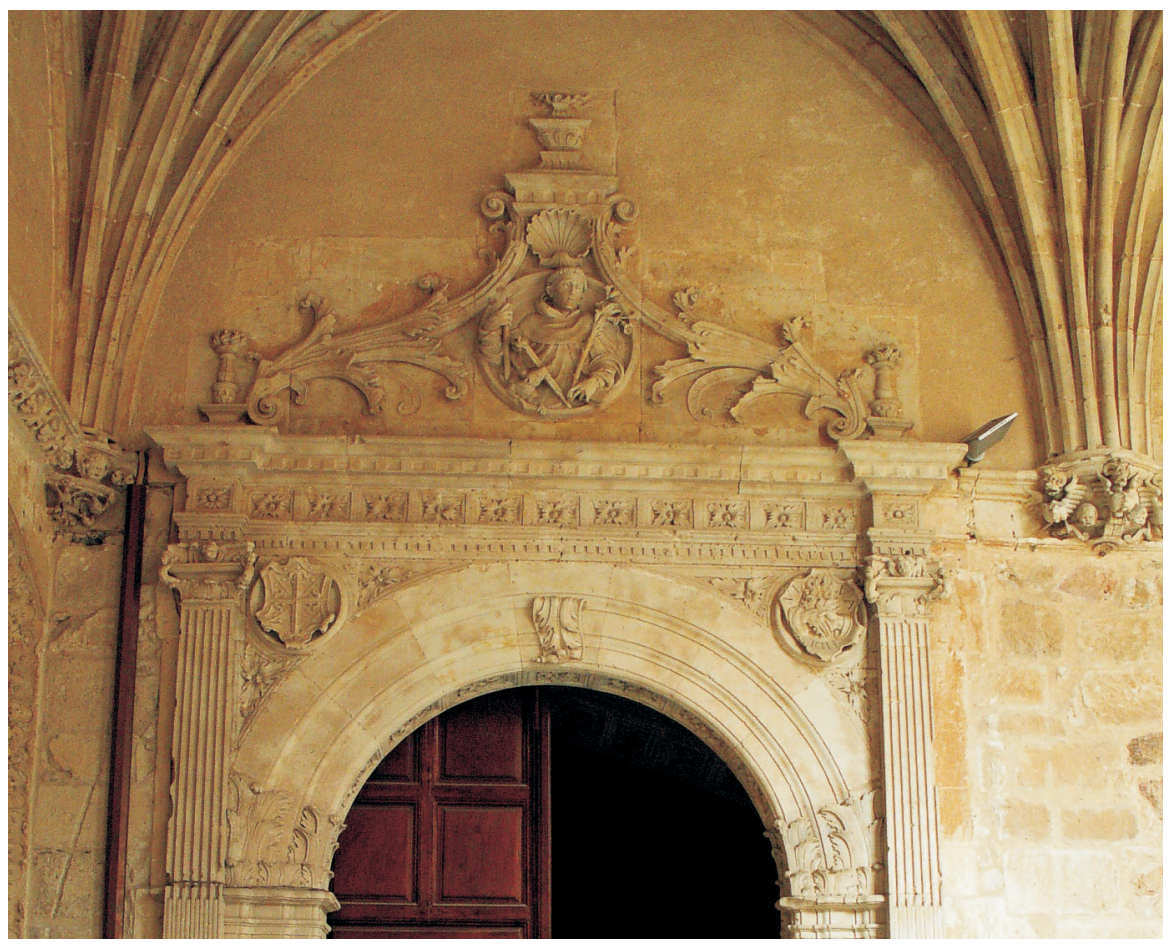

Fig. 1. Puerta de Santo Domingo, costeada por fray Domingo de Soto h. 1556. Claustro de los Reyes. Salamanca. Convento de San Esteban.

Como acabamos de señalar, esta portada se contrató veinte años antes de que se realizase la del nuevo Capítulo, que hasta el momento se suponía había marcado la pauta para las otras cuatro $^{9}$. En la parte que da al claustro principal, se pretendió una armonización con la puerta existente al otro extremo de la crujía, costeada por fray Domingo de Soto y probablemente construida por Rodrigo Gil de Hontañón hacia $1556^{10}$ (fig. 1), pero al mismo tiempo se buscó un mayor enriquecimiento ornamental, como ponen claramente de relieve las condiciones de la escritura. Los asentistas debían realizar "una traza corintia", que estaba en poder de fray Pedro Tapia y llevaba su firma y la de Jerónimo de Ontiveros. Esta traza guardaba hasta la cornisa una correspondencia en las molduras con la "puerta frontera de la entrada de el claustro a la sacristia" - como es patente sobre todo en el adorno con acantos de los salmeres y la clave del arco de medio punto-, pero en la escritura se advierte que la talla del friso debía ser de medio relieve y los escudos de las enjutas ovalados, "bien adornados" y con las armas de la Orden. Encima de la cornisa se debía poner un santo "en un espejo mayor que el de la puerta frontera", y sobre él

\footnotetext{
9 Según Rodríguez G. De Ceballos, La iglesia y el convento..., ob. cit., p. 100-101 y 135, la construcción de la puerta del Capítulo en 1634 había originado el que se agrandasen y modificasen las puertas restantes a tenor del nuevo estilo, pero posiblemente fue la última que se construyó y la que más se aparta del modelo. De hecho dispone sobre el friso una prominente cornisa con frontón curvo partido para albergar una hornacina con la estatua de San Esteban en lugar del medallón que aparece en las otras cuatro. Por su parte, Espinel la fechó en 1591, tomando como pie la terminación de la obra de la portería (Espinel, J. L., San Esteban de Salamanca. Historia y Guía (Siglos XIII-XX). Salamanca, Editorial San Esteban, edic. de 1995, p. 253).

${ }^{10}$ Rodríguez G. De Ceballos, A., La iglesia y el convento..., ob. cit. p. 94.
} 




Fig. 2. Puerta de San Pedro Mártir, que da paso a la portería. Claustro de los Reyes. Salamanca. Convento de San Esteban.

estaba previsto colocar una venera con su "remate vien lavrado y adornado, y ençima de él una pirámide con su vola"; los pedestales llevarían también "las armas de la Orden" y a plomo de las pilastras se pondrían dos pirámides, pero teniendo en cuenta que las molduras que acompañasen al santo debían ir "vien poblados de ojas e ramos e que suvan y vajen, más que los que están fechos en la puerta frontera correspondiente"11 (fig. 2).

${ }^{11}$ Las condiciones de esta portada en AHPS, Prot. 3753, doc. cit. en nota 6. 
Libre de este condicionamiento anterior, el tratamiento varía por completo en el envés de esta misma puerta, hasta el punto de no considerarse obra de los mismos artífices. En este caso se buscó un estilo más sobrio, acorde con la propia portería. La puerta sería adintelada en lugar de medio punto, enmarcada "con puntas de diamante o florones" y flanqueada por pilastras dóricas con su correspondiente arquitrabe, friso y cornisa. El friso debía llevar florones o puntas de diamantes y serafines, y sobre la cornisa pirámides a plomo de las pilastras, cuyos pedestales se adornarían con las armas de la Orden. Sobre la puerta se dispondría un nicho avenerado, enmarcado también por pilastras y frontispicio quebrado, con pirámides a los lados y un escudo en el centro "de las armas que les dijeren". En el nicho se colocaría la talla de un santo de cuerpo entero, de entre cuatro y medio y cinco pies de alto, y a los lados "dos escudos vien adornados con las armas o talla que nos ordenaren que pongamos".

Fray Pedro de Tapia debió seguir paso a paso la construcción y fue marcando las pautas hasta obtener un resultado estético a su gusto. Su intervención no es pura suposición, sino que está contemplada de manera específica en varias cláusulas de la escritura, y no hay duda de que la ejerció. Se señala en concreto que el padre fray Pedro de Tapia y quien él nombrare, podrían "quitar, poner o mudar las cosas e lavores que le parezieren", estando Miguel de Ontiveros y su hijo obligados "a azer y ejecutar la ovra conforme a la mudança u arbitrio que el dicho fray Pedro de Tapia nos diere y le pareciere y el mismo arvitrio tenga el dicho padre fray Pedro de Tapia en todo el discurso de la fábrica quando vamos edificando asta que se acave". Podría también utilizar un escultor de su satisfacción para la obra a costa de los asentistas, y asimismo debía dar su aprobación a la piedra empleada (que había de ser "muy blanca y limpia a contento del dicho fray Pedro de Tapia") ${ }^{12}$.

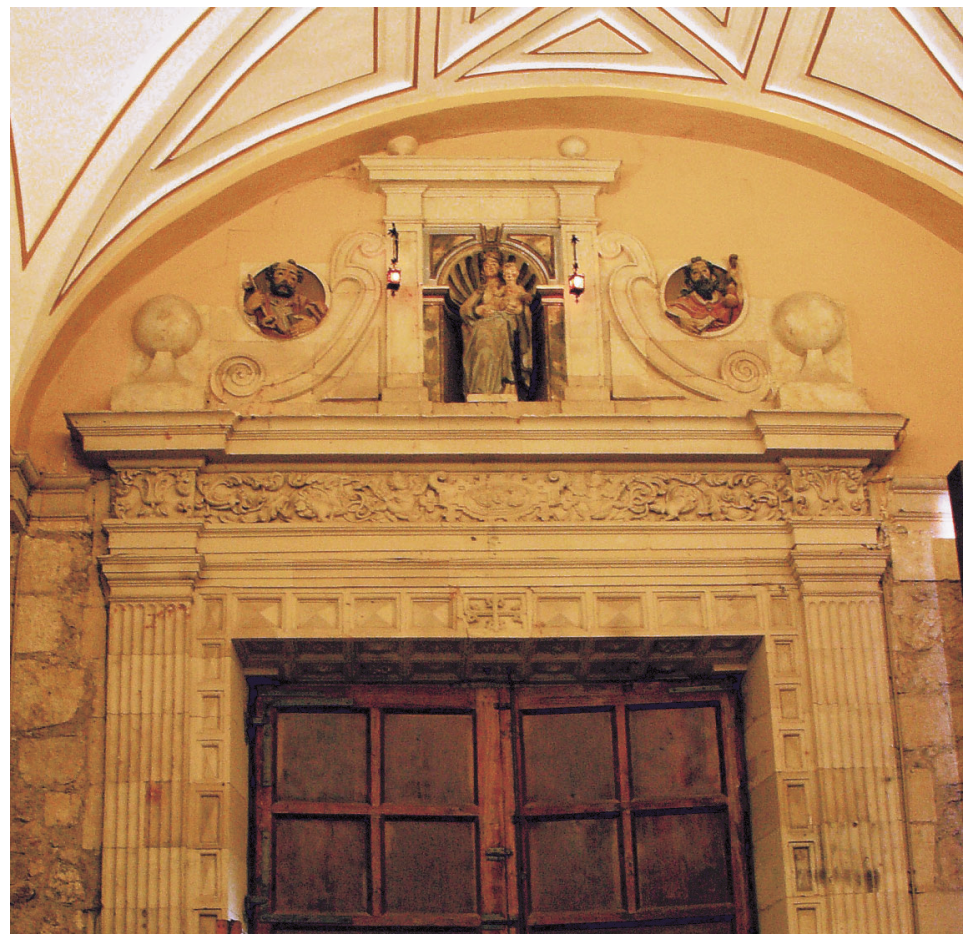

Fig. 3. Puerta de acceso al Claustro de los Reyes desde la portería. Salamanca. Convento de San Esteban.

\footnotetext{
12 Ibidem.
} 
Ejerciendo la libertad que se había reservado, este religioso decidió que se colocase una Virgen con el Niño en el nicho de la puerta que da a la portería, por la devoción que tanto él como su hermano fray Diego le tenían, como buenos hijos de Santo Domingo (fig. 3). Asimismo, en lugar de los escudos previstos en la traza inicial, mandó poner a los lados dos medallones con las efigies de San Pedro y de Santiago, en lugar de San Pablo como suele ser habitual, porque lo que pretendía era honrar a su santo patrón y al de su hermano, como señala su biógrafo Lorea ${ }^{13}$. San Pedro lleva como atributos una llave y un libro cerrado, y Santiago el bastón de peregrino con la calabaza y otro libro, esta vez abierto. Desconocemos quién fue el tallista, pero no tienen la delicadeza de otros medallones; quizá por ello se completaron con policromía ${ }^{14}$. Por lo demás, este cuerpo superior resulta muy desproporcionado respecto al inferior y acentúa el descentramiento de la puerta, cuyo tamaño y disposición vienen determinados por la puerta que se abre en el claustro.

En esta portada también se introdujeron algunas modificaciones con respecto a lo señalado en la escritura, especialmente en el ático, donde la decoración adopta una disposición triangular que se ajusta perfectamente al espacio delimitado por los nervios de la bóveda. En el centro destaca el medallón dedicado a San Pedro Mártir de Verona, dentro de una tarjeta sostenida por ángeles, que volvemos a encontrar de nuevo sobre las pilastras y en la parte superior, en sustitución respectivamente de las pirámides y de la venera prevista en un principio a imitación de la puerta frontera. Los cueros recortados que se emplean resultan todavía muy manieristas, abundando también vegetales, putti y algunos animales de carácter agrutescado, especialmente en el friso, que dan al conjunto una apariencia un tanto retardatoria respecto al momento de su construcción, mucho más clasicista (fig. 2). Esta apariencia debió buscarse intencionadamente para lograr una armonización con el estilo del claustro.

San Pedro Mártir aparece con sus atributos habituales: el cuchillo en el cráneo, la espada en el pecho, un libro en el que se lee la palabra "Credo" y la palma con tres coronas como símbolos de su martirio, predicación y castidad. La representación de este santo dominico en esta portada respondería no sólo al hecho de ser uno de los más venerados de la Orden, sino también a la coincidencia de su nombre con el del comitente: Pedro de Tapia. Por otra parte, la humildad que ensalzan los biógrafos de este religioso se pone de relieve en su renuncia a poner sus armas en la portada, como había hecho Domingo de Soto en la puerta frontera, y harán posteriormente fray Íñigo Brizuela o fray Pedro de Herrera en el capítulo y en la sacristía respectamente. Las alusiones a su persona son tan sutiles que no es de extrañar que, pasado un tiempo, cayesen en el olvido.

Miguel y Jerónimo de Ontiveros ajustaron el coste de esta portada, con su haz y envés, en dos mil ochocientos reales, pagaderos en tres plazos. Unas semanas después, el 7 de marzo de 1614, Hernando Guisado, como principal, y los también carpinteros Pedro de Atovo y Antonio de Herrera y el cerrajero Miguel Hernández como sus fiadores, se obligaron a hacer "dos puertas grandes con dos postigos para la portada que se aze de la entrada de la portería a el claustro de el convento de san Estevan". Los entrepaños de las mismas serían de nogal y el resto de vigas de pino, con sus molduras "a dos hazes tanto a la una parte como a la otra", "y hacia la parte del claustro en arco... y por la parte de la portería a de yr quadrada". También aquí se debía contar con la aprobación de fray Pedro de Tapia, a cuya disposición quedaría "la labor" que habían de

\footnotetext{
13 LOREA, ob. cit., p. 14.

${ }^{14}$ Muerto en 1611 Diego Salcedo, que había realizado los medallones del cimborrio con bustos de los Evangelistas y Padres de la Iglesia, también policromados, es posible que fray Pedro de Tapia recurriese a Pedro Hernández, que había tenido contactos con aquél. Consta que en 1739 se retocó la pintura de los dos apóstoles y de Nuestra Señora, después de haberse blanqueado la portería. Archivo del Convento de San Esteban. "Libro Nuevo de Memoria que començó a escribirse el año 1736...”, fol. 134r.
} 
hacer en las puertas y también debían ser "a contento de dicho padre" los oficiales que metieran. El precio se ajustó en 750 reales, corriendo el herraje y postigos por cuenta del convento ${ }^{15}$.

La portería de San Esteban se completó con la sustitución en 1615 del empedrado que hasta el momento cubría el suelo, por un enlosado de piedra granítica de Ledesma o de los Santos con cintas de pizarra de Mozárbez, de características similares a las del claustro. Se obligaron a ejecutarlo de nuevo Jerónimo de Ontiveros y Cristóbal de Tolosa, como su fiador, "a contento del padre superior, del padre fray Pedro de Tapia" o de fray Antonio Vázquez, que firmó con ellos el concierto, lo que indirectamente nos indica que los religiosos habían quedado satisfechos con el trabajo realizado por estos canteros en la portada. El precio se fijó en 2.200 reales, si bien Ontiveros podía quedarse con los despojos del guijarro grueso y la pizarra del empedrado anterior. Las dos puertas de esta portería, que comunicaban con la calle y el claustro, debían quedar enlosadas del mismo modo que la puerta de la iglesia que estaba junto a la de la sacristía, y con una simple pizarra larga la que salía al corral y la que daba al peso. También en este caso la intervención de fray Pedro de Tapia fue muy activa: aprobar los materiales utilizados, decidir sobre la elevación o no del nivel de la portería hasta igualarlo con el piso del claustro, con el consiguiente levantamiento de las puertas $\mathrm{y}$, en caso necesario, tomar oficiales para terminar la obra si no estaba concluida para la Ascensión. No mucho después de esta reforma, fray Pedro de Tapia dejó definitivamente el convento de San Esteban, pero su iniciativa marcó el modelo de las portadas que se fueron abriendo en el claustro.

La puerta que lo sigue con más fidelidad es la que en los documentos llaman puerta "para las andas". Daba paso a la antigua capilla de los Carvajal, en la que probablemente se había decidido guardar "las andas, carro triunfal o custodia de plata", una obra excepcional que había concluido el platero vallisoletano Juan Lorenzo en 1620. Su coste había ascendido a más de 8.210 ducados $^{16}$. El procurador del convento, fray Joan Contador, en virtud del poder que tenía de la comunidad, concertó la construcción de esta nueva puerta el 17 de julio de 1623 con el maestro de cantería Francisco de la Hoya. Unos años después volvemos a encontrarlo trabajando en la nueva Sala Capitular con Juan Moreno y Alonso Sardiña ${ }^{17}$, pero en esta ocasión no se le dejó mucho margen de iniciativa. Debía limitarse a "executar en ella la planta de la puerta de la portería que sale al claustro por la az del mismo claustro, que sólo a de bariar en que en lugar de san Pedro mártir a de poner un san Jacinto con nuestra Señora en una mano y en la ottra una custodia del Santísimo Sacramento confforme a la posición que pidiere el arte"18. Precisamente el hecho de que San Jacinto tenga como atributo una custodia pudo determinar el que se eligiese para representarlo en esta "puerta para las andas", mientras en el entablamento se recuerda la antigua pertenencia de la capilla a doña Beatriz de Carvajal y a su marido don Diego de Ávila, mediante una inscripción y la disposición de sus armas sostenidas por putti. No obstante, aparte del distinto tratamiento de la talla, la única innovación frente al modelo es la presencia de dos óculos a los lados del ático, decorados con cueros recortados (fig. 4). Si la obra siguió la marcha prevista, la portada se habría terminado en San Lucas de este año con un coste de mil novecientos cincuenta reales.

15 AHPS, Prot. 3753, "Escritura entre el convento de san Estevan e Hernando Guissado, maestro de carpintería, en 7 de março de 1614”, ff. 274r.-275. No era la primera vez que Guisado trabajaba para este convento. Unos años antes, en 1604, se había ocupado de rehacer algunos tejados de la iglesia y de las capillas, cf. HeRnÁNDEZ, art. cit., p. 279.

16 “Libro Nuevo de Memoria...,", doc. cit., ff. 83 y ss. Rodríguez G. De Ceballos, La iglesia..., ob. cit., p. 78.

${ }^{17}$ Ibidem, p. 116, nota 51. A partir de 1626 también ejecutó con Juan Moreno y Juan de Rioseco las trazas del convento del Carmen Calzado realizadas por fray Alonso de San José. Asimismo, en los años treinta contrató con Juan Moreno la torre de la Colegiata de Tordesillas, intervino en el crucero y cúpula de los Agustinos y ejerció como aparejador en la iglesia de las Agustinas. Velasco Bayón, B., El Colegio Mayor Universitario de Carmelitas de Salamanca, Salamanca, Centro de Estudios Salmantinos, 1978, pp. 53-54. Madruga Real, A., Las Agustinas de Monterrey, Salamanca, Centro de Estudios Salmantinos, 1983, p. 83.

${ }^{18}$ AHPS, Prot. 3762, Scriptura en ffavor del convento de San Estevan. 17 de julio de 1623 años, ff. 325r.-326r. 
Fig. 4. Puerta de San Jacinto. Claustro de los Reyes. Salamanca. Convento de San Esteban.

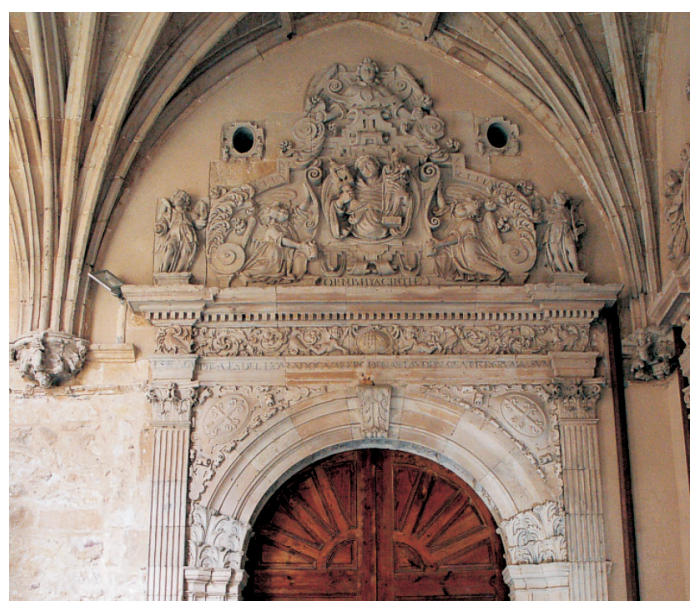

Fig. 5. Puerta de San Gregorio Magno. Claustro de los Reyes. Salamanca. Convento de San Esteban.

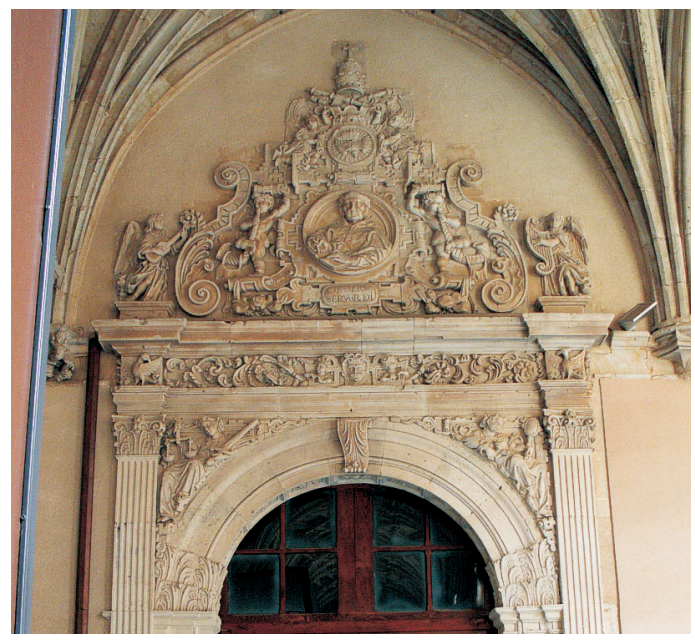

Fig. 6. Puerta de Santo Tomás. Claustro de los Reyes. Salamanca. Convento de San Esteban.

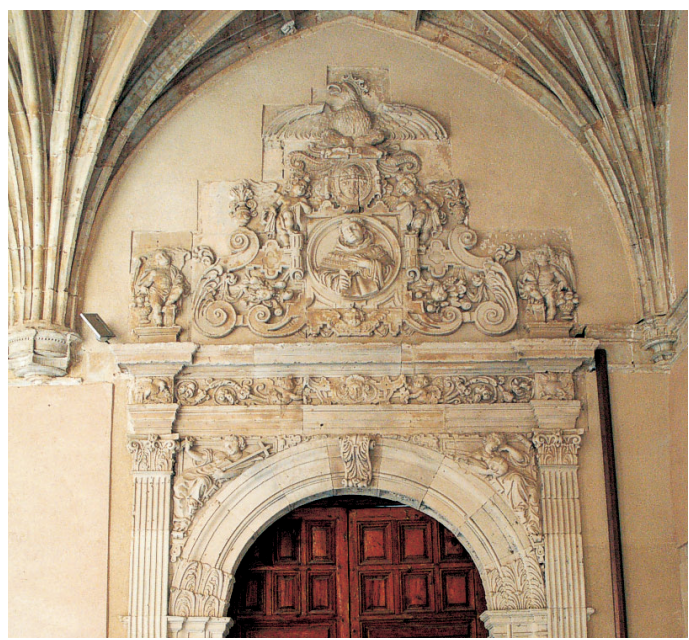

AEA, LXXXI, 321, ENERO-MARZO 2008, 67-76, ISSN: 0004-0428 


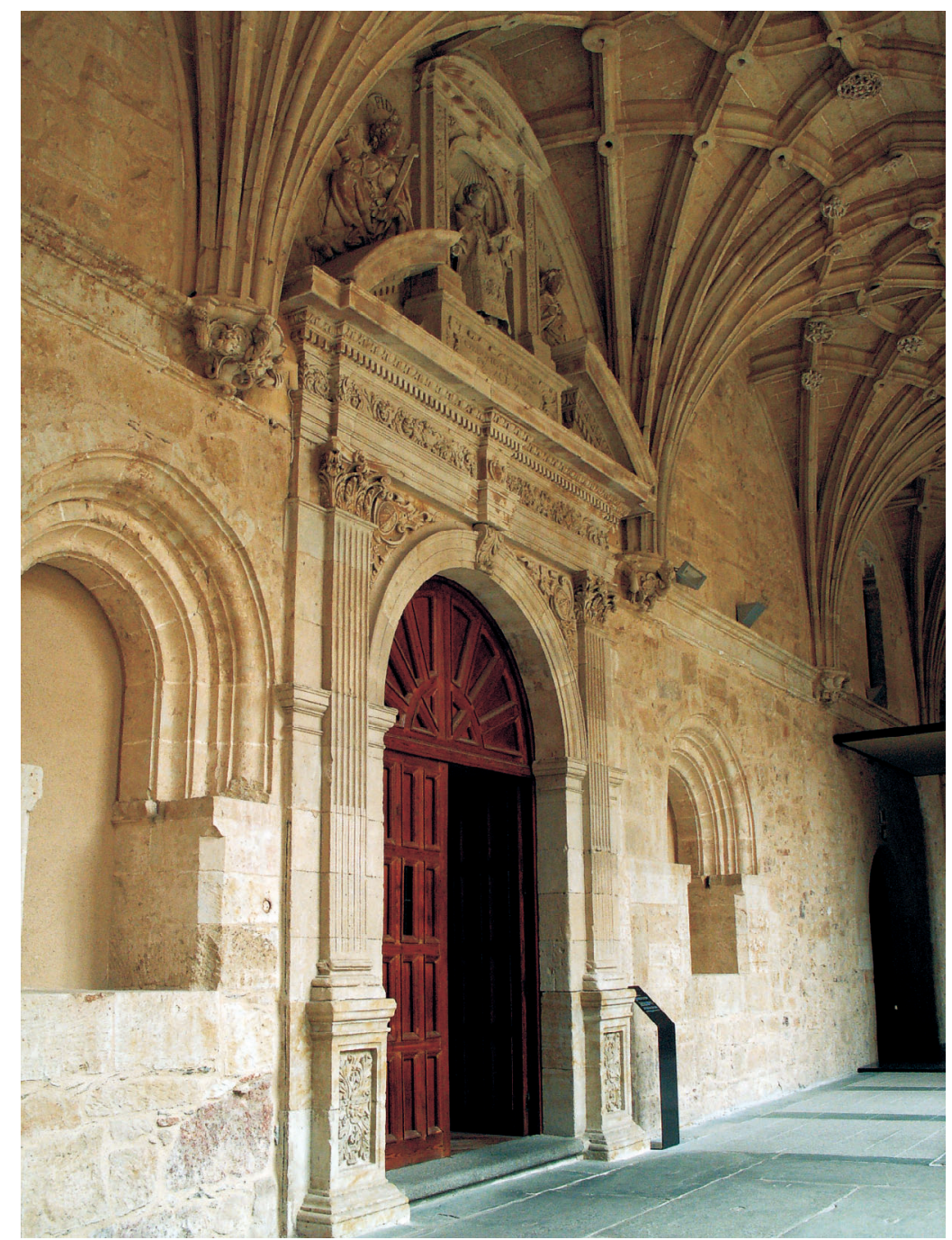

Fig. 7. Puerta de ingreso a la Sala Capitular Nueva. Claustro de los Reyes. Salamanca. Convento de San Esteban.

A esta puerta seguirían las de Santo Tomás y San Gregorio Magno, que comunican con las dependencias conventuales del segundo claustro y el salón de Profundis, respectivamente (figs. 5 y 6). En este caso, si bien en líneas generales siguen el mismo modelo, introducen un mayor número de elementos simbólicos con las modificaciones consiguientes, como la representación de virtudes en las enjutas en lugar de los escudos dominicanos, la sustitución de los ángeles tenantes por putti tocando cuernos o con cestos de frutas, la conversión de otros en ángeles músicos o la disposición sobre los medallones de atributos propios de los santos representados. En este caso no tenemos constancia de su construcción, pero posiblemente fue entre 1623 y 1634, cuando se contrató la del Capítulo, que como ya hemos señalado modifica por completo la interpretación del ático seguida en las otras puertas (fig. 7).

NIEVES RUPÉREZ Universidad de Salamanca 